- This is a report of a clinical audit carried out by a general dental practitioner

- The use of Index of Treatment Need (IOTN) and Peer Assessment Rating (PAR) indices is discussed

- Consecutively completed orthodontic cases were scored using both IOTN and PAR indices and compared with other published results

- Good results can be achieved by general dental practitioners

- It is hoped that others will be encouraged both to carry out audit and publish their results

\title{
A 10-year retrospective audit of consecutively completed orthodontic treatments in a general dental practice and a hospital orthodontic department
}

\section{E. J. Atkins ${ }^{1}$}

\begin{abstract}
During 1993 and 1994, the author took part in the South West Orthodontic Clinical Assistant Training Programme and worked as a part-time Clinical Assistant in the Orthodontic Department of the Royal United Hospital, Bath. Following the clinical assistantship the author continued to treat patients in the hospital department but under a General Dental Services contract number. This paper is a personal clinical audit of all the orthodontic cases completed within the GDS by the author since 1990, both in general practice in Westbury, Wiltshire and at the Royal United Hospital (RUH), Bath. The aim of the audit was to evaluate the effectiveness of orthodontic treatment carried out by the author, both in general dental practice and in a hospital orthodontic department, and to compare treatment outcomes with other published results.
\end{abstract}

The quality of orthodontic treatment provided within the General Dental Services (GDS) in England and Wales has often been questioned. Various studies, looking at orthodontic treatment within the GDS as a whole, have shown that a high proportion of patients showed little improvement, especially when treatment only involved the use of removable appliances. ${ }^{1-5}$

The cost to the NHS of GDS orthodontic treatment has doubled over the past 5 years to an estimated $£ 80$ million. ${ }^{6}$ It has been suggested that both the quality and expenditure could be controlled by restricting the provision of orthodontic treatment to those with a specialist orthodontic qualification. ${ }^{7}$ Furthermore, it has also been suggested that only those patients with an Index of Treatment Need (IOTN) dental health component of 3 and above should receive orthodontic treatment. ${ }^{8}$

\section{${ }^{1}$ GDP, 29 Haynes Road, Westbury, Witshire BA13 $3 \mathrm{HB}$ \\ Correspondence to: EJ Atkins \\ E-mail:eejay@dial.pipex.com}

\section{Refereed Paper}

Received 25.04.01; Accepted 05.12.01

๑ British Dental Journal 2002; 193: 85-87
Some studies have shown that, following suitable training, general dental practitioners can produce results which compare favourably with those achieved in the GDS as a whole. $^{9,10}$ Although personal audits have been published by those working in the hospital service, ${ }^{11,12}$ no such studies have been published by general dental practitioners who do not hold a postgraduate orthodontic qualification.

\section{AUDIT}

There are two indices which are used to assess the need for orthodontic treatment and the standard of treatment provided. These are the Index of Treatment Need (IOTN) and the Peer Assessment Rating $(\mathrm{PAR})^{13}$ respectively. Since their introduction, they have been extensively used in epidemiological studies as well as for monitoring and promoting standards. ${ }^{14}$ The IOTN attempts to rank malocclusion in terms of severity, in order to identify those individuals who would most benefit from orthodontic treatment. It incorporates both aesthetic and dental health components. In this study only the dental health component was used.
The PAR index was developed to provide a quantitative objective method of measuring malocclusion and efficacy of treatment. The degree of improvement can be assessed in two ways. Using a nomogram, the PAR score can be plotted on a graph that is divided into three sections: 'Greatly Improved', 'Improved' and 'Worse or No Different' (Fig. 1). The alternative and more sensitive assessment of improvement is to use the percentage change in the PAR score relative to the pre-treatment score.

Using these indices, the study models of 107 consecutively completed orthodontic cases treated by the author were scored for pre-treatment IOTN and pre- and posttreatment PAR. This was performed by one of two orthodontic technicians both of whom had been trained in the use of these indices. The patients' age and sex, length of treatment and type of appliance were also recorded. These cases represented all those completed within the GDS by the author, both in practice since 1990 and in the hospital since 1995, apart from three whose models were not available (one from the practice, two from the hospital). In this same time period, there were also ten dis- 
End PAR

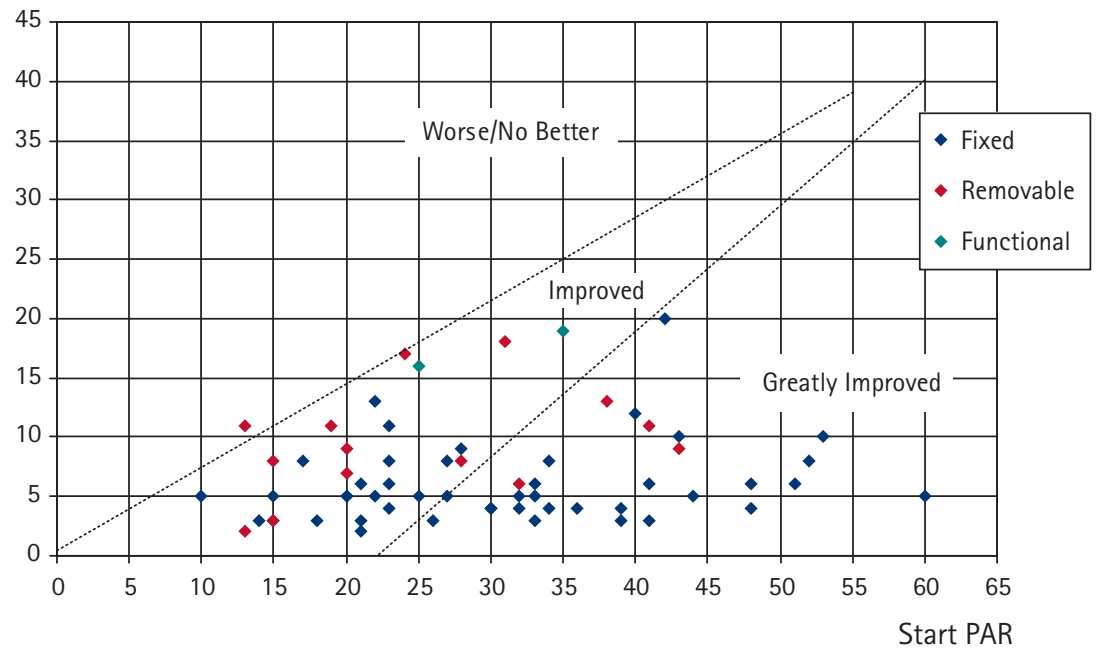

Fig. 1 PAR nomogram for completed cases (practice) by appliance

continued cases (two from general practice and eight from the hospital) that were not included in the audit. Sixty-two of the cases were treated in general practice and 45 within the hospital under the GDS (Fig. 4).

The results were recorded and analysed with a computer spreadsheet.

\section{FINDINGS}

\section{IOTN}

Eighty-two per cent of patients treated in general practice and 98\% of patients treated in the hospital had an initial IOTN dental health component score of 3 or more. More than half had an initial IOTN score of 4 or more (general practice 58\%, hospital 87\%). If the aesthetic component of IOTN had been recorded it is possible the number who would fall into the requiring treatment category might be even higher. The number of cases treated would, therefore, not be greatly affected if, as previously mentioned, the provision of orthodontic treatment in the GDS is limited to an IOTN of 3 or more. Of interest is that, although there was a higher proportion of patients with an IOTN of 3 or less treated in general practice, there also was a higher proportion with an IOTN of 5. (Fig. 2) This may be caused by the limitations of IOTN, in that it is not an index of treatment complexity but of need. For instance, a malocclusion consisting of a reversed incisor overjet may only score an IOTN of 2 but correcting it could produce a worthwhile reduction in PAR score. Furthermore, it may not follow that a high start IOTN will produce a greater percentage reduction in PAR score following successful treatment. (Fig. 3)

\section{PAR score}

Previously published personal audits suggest that, to achieve a good standard of orthodontic treatment, the mean reduction in the PAR score should be greater than $70 \%$. Alternatively, the number of patients falling into the 'Worse or no different' category should ideally be less than $5 \% .{ }^{15}$ Overall, 99\% of all cases examined in this audit were either 'Improved' or 'Greatly Improved', with a mean percentage reduction in PAR of 77.

\section{Clinical assistant training programme}

The results achieved in general practice, as assessed using the PAR index, were comparable to those treated by the author within the hospital but under the GDS, with all cases falling into the 'Improved' or 'Greatly Improved' category (Fig. 4). From 1994 onward, 100\% of the patients examined could be classed as 'Improved' or 'Greatly Improved'. These 97 patients had a mean pre-treatment PAR score of 30.3, which fell to a post-treatment score of 6.1.

Although the number of cases in this audit are too small to determine if clinical assistant training has had an effect on treatment outcome, the standard of orthodontic treatment provided by general dental practitioners, in their practices, after the completion of a 2-year clinical assistant training programme has been examined by two previous studies. Stratford et al. looked at 166 patients and found that the mean pre treatment PAR score of 20.7 fell to a post treatment score of $9.2^{16}$ whilst Power et al. found that $83 \%$ of the 172 patients examined could be classed as 'improved' or 'greatly improved. ${ }^{17}$
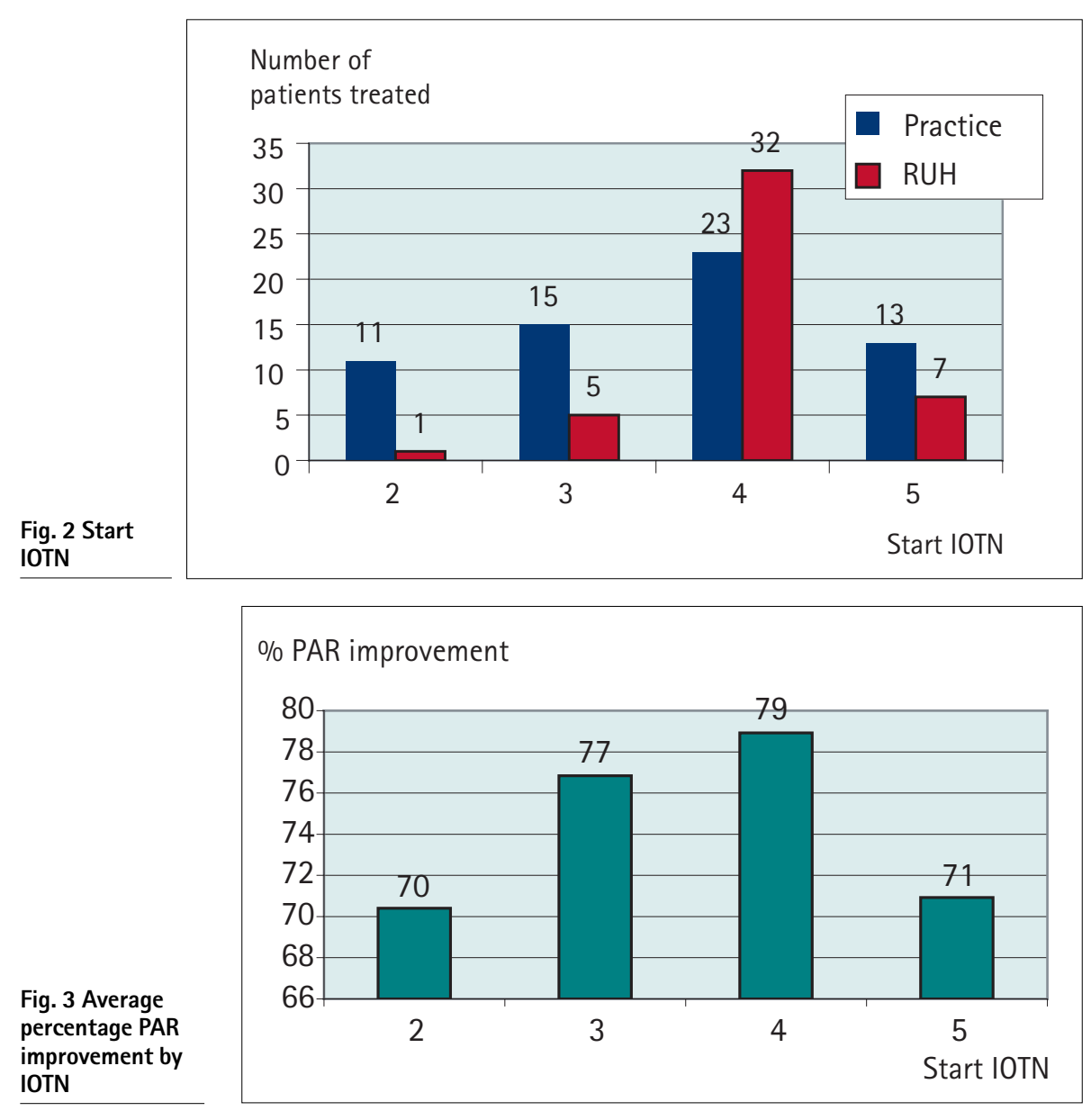


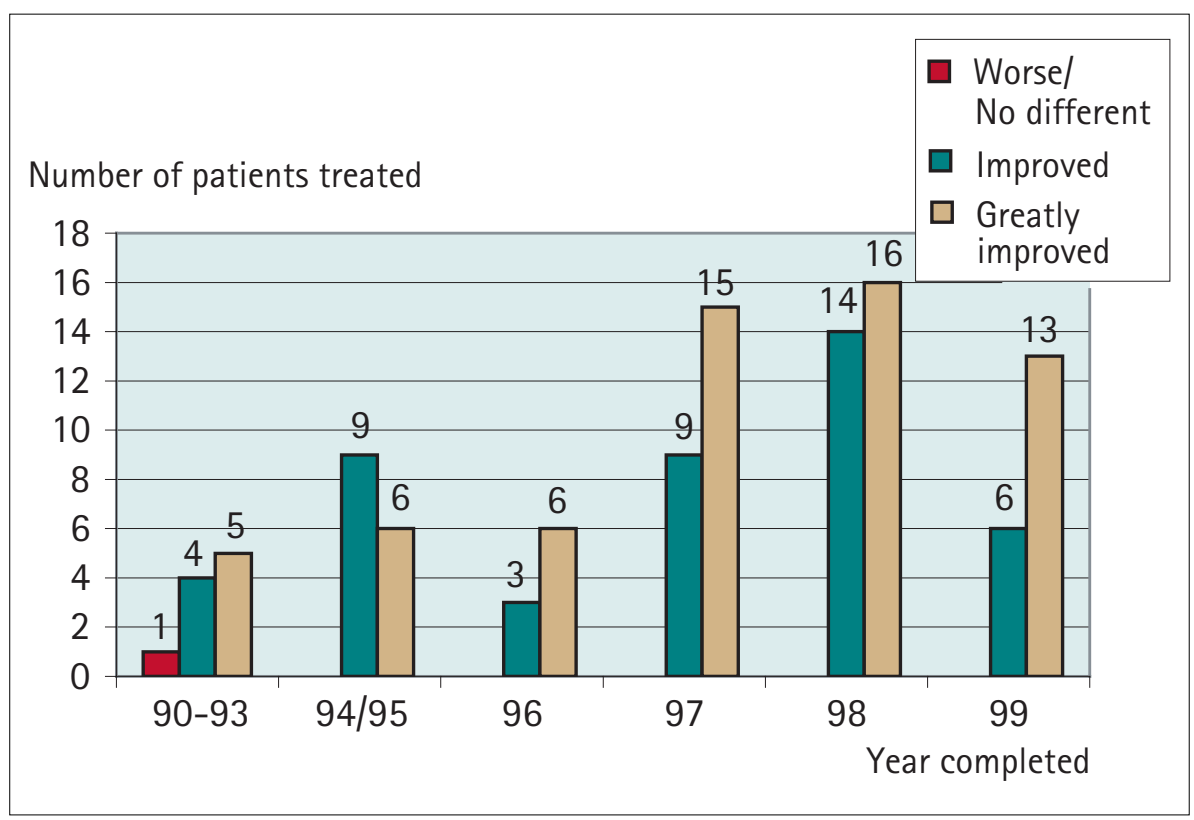

Fig. 4 Improvement by date

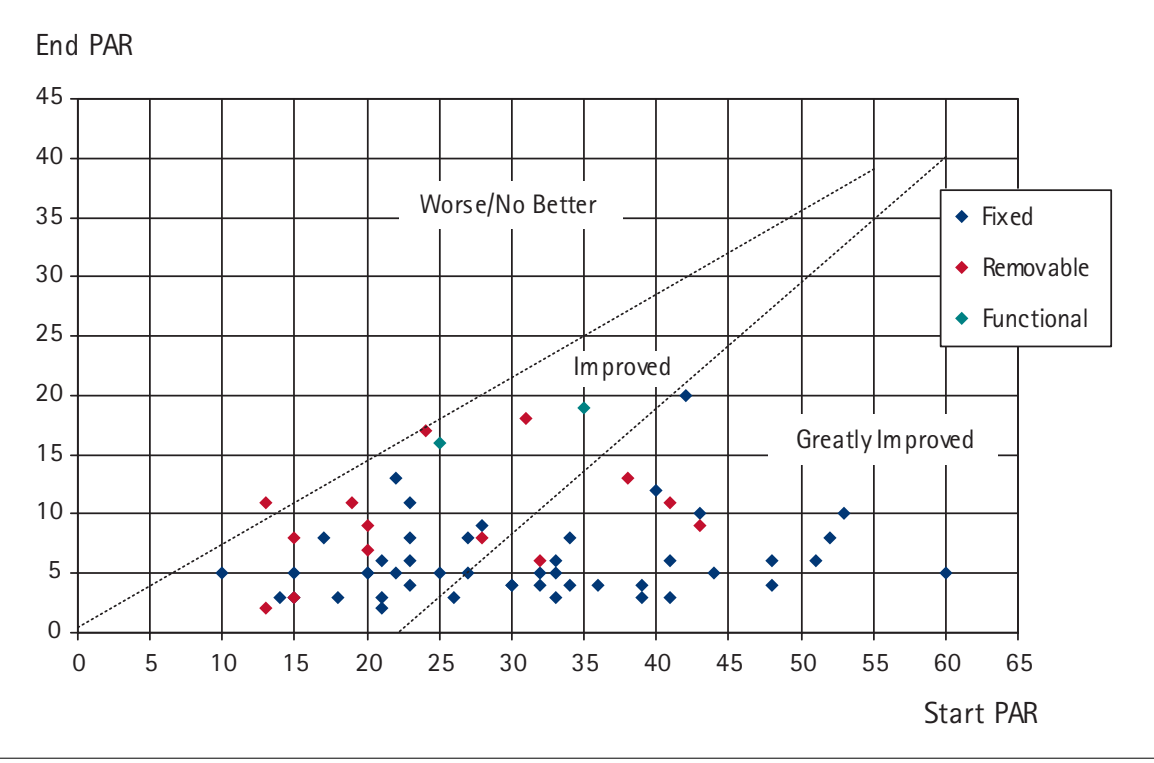

Fig. 5 PAR nomogram for completed cases (RUH) by appliance

\section{Type of appliance}

There was a slightly lower percentage PAR reduction in the scores of those cases treated in general practice compared with those treated in the hospital department. (Figs. 1 and 5) One reason for this may be that the type of appliance used influences treatment outcome and a greater number of patients were treated only with removable appliances in general practice. This is supported by other published findings, ${ }^{18}$ which show that fixed appliances produce a significantly better result than when removable appliances alone are used. To investigate this hypothesis, a future audit could perhaps look in more detail at treatment outcomes of different appliance therapies carried out by the same operator.

\section{CONCLUSION}

As clinical governance is now a mandatory part of the GDS regulations, this report will hopefully encourage more practitioners to carry out and publish audits of their own treatment results. Orthodontics is just one area of general practice where firm evidence is needed in order to establish a baseline from which to measure quality. With more evidence available, the value of treatment provided in the GDS can then be properly assessed.

The author would like to thank Dr A. J. Ireland, Orthodontic Consultant, Royal United Hospital, Bath, and Mr P. Gabb and Mr G. Cordall, Orthodontic Technicians, Royal United Hospital, Bath, for their help in preparing this paper.

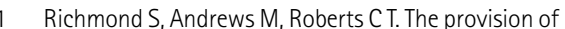
orthodontic care in the GDS of England and Wales: extraction patterns, treatment duration, appliance types and standards. Br J Orthod 1993; 20: 345-350.

2 Kerr W J S, McColl J H, Frostick L. The use of removable orthodontic appliances in the GDS. Br Dent J 1996; 181: 18-22.

3 Turbill E A, Richmond S, Wright J L. A critical assessment of orthodontic standards in England and Wales (1990-91) in relation to changes in prior approval. Br J Orthod 1996; 23: 221-228.

4 Fox N A, Richmond S, Wright J L, Daniels C P. Factors affecting the outcome of orthodontics treatment within the GDS. Br J Orthod 1997; 24: 217-221.

5 Teh LH, Kerr W J S, McColl J H Orthodontic Treatment with Fixed Appliances in the General Dental Service in Scotland. Br J Orthod 2000; 27: 175-180.

6 Modernising NHS Dentistry-Implementing the NHS Plan. London: Department of Health, September 2000, pp35, s. 4.32.

7 Robin Wild, Chief Dental Officer for England and Wales. 'Science of the Appliance' - Address to the British Orthodontic Conference, Glasgow, September 1999.

8 Department of Health, op. cit., pp36, s. 4.35.

9 Stratford N M, Burden D J. Clinical assistant training in orthodontics - how effective is it? BrDent J 1998: 184: 448-452.

10 Power S M, Hodgkins J F, Stephens C D, Webb W G. An investigation into the standard of orthodontic treatment carried out by GDPs after completion of a clinical assistant training. Br Dent J 1996; 180: 91-97.

11 Fox N A. The first 100 cases, a personal audit of orthodontic treatment assessed by the PAR (Peer Assessment Rating) Index. BrDentJ 1993: 174: 290-297.

12 Richmond S. Personal audit in orthodontics. BrJ Orthod 1993; 20: 131-145.

13 Richmond S, O'Brien K, Buchanan I, Burden D. An Introduction to Occlusal Indices. Manchester: Mandent Press, 1992.

14 Shaw W C, Richmond S, O'Brien K D, Brook P and Stephens C D. Quality Control in Orthodontics: Indices of Treatment Need and Treatment Standards. 1991: BrDent J 107-112.

15 Richmond S op cit

16 Stratford N M, Burden D J. op. cit.

17 Power S M, Hodgkins J F, Stephens C D, Webb W G, op. cit.

18 Richmond S, Shaw W C, Stephens C D, Webb W G, Roberts C T, Andrews M. Orthodontics in the General Dental Services of England and Wales: a critical assessment of standards. Br Dent J 1993; 174: 315-219. 